\title{
Hava Lidar verilerinin denetimsiz yapay sinir ağları kullanılarak filtrelenmesi
}

\author{
Alper Şen ${ }^{1^{*}}$ D , Burcu Bayaslı1 ${ }^{1}$ (D) \\ ${ }^{1}$ Yıldız Teknik Üniversitesi, Davutpaşa Kampüsü, Inşaat Fakültesi, Harita Mühendisliği Bölümü, Esenler, İstanbul, Türkiye.
}

Öz: Hava Lidar (Light Detection and Ranging) sistemleri ile üretilen mekânsal veriler, yüksek doğruluklu, hızlı ve az maliyetli olarak elde edilmektedir. Ancak verilerin nesne çıkarımı amacıyla elle işlenmesi, zaman alan ve emek yoğun bir işlemdir. Bu süreci otomatik bir hale dönüşürmek amacıyla, denetimli/denetimsiz sinıflandırma yöntemleri kullanılabilmektedir. Lidar verilerinin, zemine ait ve zemine ait olmayan veriler olarak ayrılmasına filtreleme denir. Lidar verileri kullanılarak Sayısal Yükseklik Modeli oluşturulmasında filtreleme işlemi büyük önem arz etmektedir. Bu çalışmada, Harita Genel Müdürlüğ̈̈nün başkanlığında 2014 yılında üretilen, Riegl LMS-Q1560 Lidar sistemiyle Bergama ilçesinde 1200 metre yükseklikte gerçekleştirilen uçuş verilerinden elde edilen ayrlk-dönüşlü Lidar test verisi kullanılmıştır. Lidar nokta bulutu, denetimsiz bir yapay sinir ağl yöntemi olan Kendini Düzenleyen Haritalar (KDH) yöntemi ile analiz edilerek kümelere ayrılmıştır. Kümeler, uydu görüntüleri ile karşılaştırılarak nesne sinıfları belirlenmiştir. Bu yöntem ile elde edilen nesne sınıflarının doğruluğu, görsel olarak sinıfları belirlenen tüm noktalar incelenerek hesaplanmıştır. Sinir ağına ait en az nöron sayısı, denetimli olarak hata değerlerine göre belirlenmiştir. Lidar nokta bulutunun KDH yöntemiyle filtrelenmesi sonucu, Tip-1 hatası \%11.54, Tip-2 hatası \%19.43 ve toplam hata \%16.41 olarak bulunmuştur. Elde edilen sonuçlara göre, hava Lidar verilerinin filtrelenmesinde KDH sinir ağlarının belirlenen nöron sayısı ile etkin olarak kullanılabildiği görülmüşü̈r.

Anahtar Sözcükler: Lidar, Yapay sinir ağları, Kendini düzenleyen haritalar, Filtreleme

\section{Filtering of airborne Lidar data by using unsupervised artificial neural networks}

\begin{abstract}
Spatial data produced with airborne Lidar(Light Detection and Ranging) systems are obtained with high accuracy, fast and low cost. However, manual processing of the data for object extraction is time consuming and labor intensive. Supervised/unsupervised classification methods can be used to make this process automatic. Classification of Lidar data as ground and non-ground data is called filtering. Filtering is very important in creating a Digital Elevation Model using Lidar data. In this study, the discrete-return Lidar test data obtained from the flight at 1200 meters altitude in Bergama district with the Riegl LMS-Q1560 Lidar system produced in 2014 under the chairmanship of the General Directorate of Mapping was used. The Lidar point cloud was grouped into clusters by analyzing it with the Self Organizing Maps (SOM), which is an unsupervised artificial neural network method. Feature classes were determined by comparing clusters with satellite images. The accuracy of the feature classes obtained by this method was calculated by examining all points of the classes which were visually determined. The minimum number of neurons of neural network was determined according to the error values. As a result of filtering the Lidar point cloud with SOM method, Type-1 error was found as 11.54\%, Type-2 error was 19.43\% and total error was $16.41 \%$. In accordance with the results obtained, it was seen that SOM neural networks with the number of neurons determined could be used effectively in filtering the airborne Lidar data.
\end{abstract}

Keywords: Lidar, Artificial neural networks, Self organizing maps, Filtering 


\section{Giriş}

Günümüzde hava Lidar (Light Detection and Ranging) sistemleri 3 boyutlu (3B) kent modellemeleri, kıyı çizgisi tespiti, peyzaj, demiryolu güzergâhları, enerji nakil hatları belirlenmesi, çevre kirliliği modellemeleri, orman alanlarının saptanması ve hatta ağaç türlerinin belirlenmesi gibi pek çok çalışmada kullanılmaktadır. Lidar teknolojisi ile veri üretimi yüksek doğruluk, hız ve zaman açısından büyük avantaj sağlamaktadır. Buna karşın, mekânsal bilgilerin çıkarımı amacıyla Lidar verilerinin elle ve/veya otomatik olmayan yöntemlerle işlenmesi kapsamlı, maliyetli ve zaman alıcıdır. Verilerden nesne çıkarımı sürecini otomatik bir hale dönüştürmek amacıyla, denetimli/denetimsiz sınıflandırma yöntemleri kullanılabilmektedir.

Lidar sistemlerinin dönüşs sinyali, kayıt tekniklerine göre ayrık dönüşlü sistemler ve tam dalga boyu formlu sistemler olarak kategorize edilir. Nokta tabanlı sınıflandırma, genellikle ayrık-dönüşlü sistemler için kullanılır. Yakalanan yükseklik özelliğine ek olarak, her gidiş ve dönüş sinyali, sinyallerin sayısı ve yoğunluğu gibi diğer nitelikleri de yakalar. Bu ek nitelikler, Lidar verilerinin analizinde kullanılabilir. Tam dalga boyu formuna dayalı sınıflandırma, bir dönüş sinyalinin tam profilini sabit zaman aralıklarında örnekleyerek kullanır. Tam dalga boyu forma sahip sistemler, orman alanlarının araştırılması gibi yoğun bitki örtüsüne sahip 3B harita üretiminde yaygın olarak kullanılır. Ancak tam dalga boyu formlu Lidar verilerinin, geleneksel ayrık-dönüşlü nokta bulutu verisine kıyasla hacmi çok büyüktür. Veri kaynağı türlerine göre mevcut sınıflandırma yöntemlerine veri füzyonu tabanlı sınıflandırma da eklenebilir. Nokta tabanlı sınıflandırma teknikleri genellikle dalga formu işleme ve/veya görüntü işleme ile veri füzyonu tabanlı yöntemlere göre hılı veri işleme sağlamaktadır (Zhang, Lin, \& Ning, 2013).

Lidar verilerinin, zemine ait ve zemine ait olmayan veriler olarak ayrılmasına filtreleme denir. Lidar verileri kullanılarak, Sayısal Yükseklik Modeli (SYM) oluşturulmasında filtreleme işlemi önem arz etmektedir (Briese 2010; Kang, Liu, \& Lin, 2014). Briese (2010) filtreleme algoritmalarını dört farklı kategoride gruplandırmıştır. Bunlar; yüzey tabanlı filtreleme, morfolojik filtreleme, segmentasyon tabanlı filtreleme ve aşamalı yoğunlaştırmadır.

Filtreleme algoritmalarının kendine has avantajları ve dezavantajları vardır. Genellikle yüzey tabanlı filtreleme algoritmaları kullanılmaktadır ve çoğu arazi koşulunda tatmin edici sonuçlar vermektedir. Bununla birlikte, bu tür filtreleme algoritmaları arazi detaylarını korumakta ve bazen küçük nesneleri sınıflandırmakta zorluk çekmektedir (Mongus \& Žalik, 2014). Yüzey tabanlı filtreleme algoritmasının aksine, morfoloji tabanlı filtreleme algoritmaları arazinin morfolojik ayrıntılarını korur. Segmentasyon tabanlı algoritmalar, farklı boyut ve şekillerdeki nesneleri algılamak için farklı özellikler kullanmaktadır. Bu nedenle, bu algoritmalar kentsel alanlar için uygundur. Bununla birlikte, bu algoritmalar dağınık lazer darbeleri nedeniyle yoğun ormanlık alanlarda zorluk çekmektedir (Chen, Gao, \& Devereux, 2017). Aşamalı düzensiz üçgen ağı yoğunlaştırma algoritması, ortalama doğruluk açısından genel filtreleme yöntemlerinde en iyi sonucu elde eder (Sithole \& Vosselman, 2004). Bununla birlikte, bu algoritma keskin sırtlar gibi süreksiz arazileri tespit etmekte zorlanmaktadır (Chen, Wang, Zhang, Sun, \& Liu, 2016).

ISPRS (International Society for Photogrammetry and Remote Sensing) çalışma grubu tarafindan farklı filtreleme algoritmalarının performansları değişik topografya özelliklerine sahip test verilerinden yararlanılarak test edilmiştir. Örneğin, 11 numaralı test verisi bitki örtüsü ve dik yamaçlarda binalar içermektedir. Çalışmada kullanılan filtreleme yöntemlerinde çoğu nesne iyi filtrelenmiştir. Merkezdeki yol, Roggero filtresi tarafından filtrelenebilmiştir. Sohn ve Sithole filtresi tarafından çok dik eğimler filtrelenebilmiştir. Teraslar, Elmqvist, Pfeifer, Roggero ve Sithole filtresi tarafından filtrelenebilmiştir. Kullanılan filtreleme yöntemlerinde Tip-1 hatası \%15.96 ile \%62 arasında değişirken; Tip-2 hatası \%2.41 
ile \%12.17 arasında değişmiştir. Toplam hata ise \%10.76 ile \%36.96 arasında değişmiştir (Sithole \& Vosselman, 2003).

Biyolojik sinir ağlarından esinlenerek makine ve bilgisayarlara öğrenebilme, tahmin edebilme ve karar verebilme yetileri sağlayan yapay zekâ ise günümüzde pek çok karmaşık problemi çözebilmektedir. Morris vd. (2005), Lidar yükseklik verisini, multispektral görüntüyü ve yapay sinir ağlarını entegre ederek Güney Carolina’da bataklık karakterizasyonunu araştırmıştır. Salah, Trinder ve Shaker (2009), multispektral hava görüntüleri ve Lidar verisinin entegrasyonundan Kendini Düzenleyen Haritalar $(\mathrm{KDH})$ yöntemiyle otomatik nesne çıkarmış ve karakteristiği farklı iki bölgede test etmiştir. Elde edilen sonuçlar, KDH yöntemiyle Lidar verisinin, yalnızca hava görüntülerinin kullanılmasına kıyasla nesne alg1lama doğruluğunu \%38 oranında geliştirdiğini göstermiştir. Zaletnyik, Laky ve Toth (2010), KDH yöntemini kullanarak Lidar verisinin dalga formunu sınıflandırmış ve bunun için geri yansıyan dalga formunun parametrelerine dayanarak kütle merkezinden hesaplanan uzaklıklar ile bitki örtüsüz yüzeyi kaldırım ve çatı kategorilerine ayırmak için kullanmışlardır. Grebby, Naden, Cunningham ve Tansey (2011) yine hava Lidar ve multispektral görüntüyü entegre etmiş ve bitki örtüsü olan alandaki litolojik sınıflandırma için KDH yöntemini kullanmıştır. Giampouras, Charou ve Kesidis (2013), yapay sinir ağları metoduna başvurarak hiperspektral özellikle entegre edilmiş Lidar verisi ile arazi örtüsünün sınıflandırılmasını gerçekleştirmişlerdir. Kwon, Jung, Baek ve Kim (2017), ortofoto ve Lidar verilerinden çok katmanlı (denetimli) yapay sinir ağlarını kullanarak orman alanlarını çıkartmış ve saha ölçümleri ile karşılaştırıldığında \%70 oranında bir başarı sağlamıştır. Şen, Süleymanoğlu ve Soycan (2020), iki farklı bölge için KDH yöntemini kullanarak ayrık-dönüşlü hava Lidar verilerini 3B koordinat ve yoğunluk özniteliğini kullanarak sınıflandırmıştır.

Bu çalışmada, Harita Genel Müdürlüğü’nün başkanlığında üretilen Bergama ilçesine ait ayrık dönüşlü Lidar test verisi kullanılmıştır. Lidar nokta bulutu KDH yöntemi ile analiz edilerek kümelere ayrılmıştır. Kümeler, uydu görüntüleri ile karşılaştırılarak nesne sınıfları belirlenmiştir. Bu yöntem ile elde edilen nesne sınıflarının doğruluğu, görsel olarak sınıfları belirlenen tüm noktalar incelenerek hesaplanmıştır. Sinir ağına ait en az nöron sayısı, denetimli olarak hata değerlerine göre belirlenmiştir. Elde edilen sonuçlara göre, hava Lidar verilerinin filtrelenmesinde KDH sinir ağlarının belirlenen nöron sayısı ile etkin olarak kullanılabildiği görülmüştür.

\section{Metodoloji}

\subsection{Kendini Düzenleyen Haritalar}

Kohonen haritası olarak da bilinen KDH ilk defa Kohonen (1990) tarafindan sunulmuştur. KDH kümeleme yöntemi veri izdüşümü ve nicelleştirmenin bir kombinasyonu olarak düşünülebilir. Yarışmacı sinir ağları olarak, çok boyutlu öznitelik uzayında benzemezlikleri ölçer. Gizli katmanı olmayan, girdi ve çıktı katmanlarından oluşan denetimsiz yapay sinir ağlarını içerir. Her nöron, girdi verisi ile aynı boyutlu referans vektörü diye adlandırılan bir vektör ile ilişkilidir.

$n$ boyutlu vektörleri içeren $x$ giriş verisi:

$x=\left[\varepsilon_{1}, \ldots, \varepsilon_{n}\right]^{T} \in R^{n}$

Burada; $\varepsilon_{i}, x$ giriş vektörüne ait öznitelik değeridir.

Her nöron bir $m_{i}$ referans vektörünü içermektedir.

$m_{i}=\left[\mu_{1}, \ldots, \mu_{n}\right]^{T} \in R^{n}$ 
Burada; $\mu_{i}, m_{i}$ referans vektörüne ait rastgele öznitelik değeridir.

Öğrenme esnasında nöronlar birbirleri ile rekabet içindedir. Giriş vektörleri, Eşitlik 3 ’te görüldüğü gibi bir mesafe kriterine göre her bir referans vektörü ile karşılaştırılır. En küçük mesafe yani en büyük benzerliğe sahip nöron rekabeti kazanır. Rekabeti kazanan nöron ve komşuları her bir giriş vektörünü öğrenerek, referans vektörlerini günceller. Sonuç olarak, birbirine en çok benzer olan giriş vektörleri kendilerine en benzer nöronlara yerleşerek, hipotetik bir elastikiyete sahip harita ağı biçimindeki nöron ağını kararlı bir yapıya dönüştürür. Topolojik öğrenme biçimi sayesinde, geleneksel yöntemlere üstünlük sağlar (Kohonen, 2001; Yan \& Thill, 2008).

$\left\|x-m_{c}\right\|=\min _{i}\left\{\left\|x-m_{i}\right\|\right\}$

Burada; $m_{c}$, minimum mesafe veya maksimum benzerlik şartını sağlayan referans vektörüdür.

KDH sürecinde ilk adım ağın boyutunu (ağın x ve y yönünde kullanılan nöron sayısı) ve topolojisini belirlemektir. Nöron ağı, kare veya altıgen topolojiye sahip olabilir (Şekil 1). Öğrenme başlamadan, n-boyutlu referans vektörleri nöronlara genellikle rastgele olarak atanır. Eğitimi etkileyen temel parametrelerden biri; referans vektörlerini güncellemek için bir mesafe-ağırlıklı model olan komşuluk fonksiyonudur. Doğrusal ve Gauss modelleri en popüler fonksiyonlardır. Rekabeti kazanan nöron (en iyi eşleşen birim) ve komşuları Eşitlik 4 ile güncellenir.

$m_{i}(t+1)=m_{i}(t)+h_{c i}(t)\left[x(t)-m_{i}(t)\right]$

Burada; $t$, iterasyon zamanını ve $h_{c i}$, komşuluk fonksiyonunu göstermektedir.

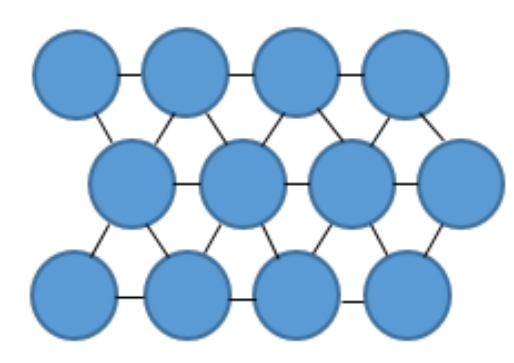

Şekil 1: Altıgen topolojiye sahip x-y yönlerinde nöron ağı

Gauss modeli:

$h_{c i}(t)=\alpha(t) \exp \left(-d_{c i}^{2} / 2 \sigma_{i}^{2}(t)\right)$

Burada; $d_{c i}$, iyi eşleşen birim ile ilişkili komşu nöron arasındaki mesafeyi; $\alpha(t), t$ zamanda öğrenme katsayısını ve $\sigma(t), t$ zamanda kernel genişliğini göstermektedir.

Gauss modelinde, komşuluk büyüklüğü kernel genişliği $(\sigma)$ ile belirlenir ve sabit bir parametre değildir. Benzer biçimde, başlangıç öğrenme katsayısı $\left(\alpha_{0}\right)$ t zamanda yavaş yavaş azalan bir giriş parametresidir. KDH, tanımlanan iterasyon sayısı tamamlandığında kümeleme işlemine son verir (Skupin \& Agarwal, 2008).

\subsection{Hava Lidar Noktalarının Sınıflandırılması}

$\mathrm{Bu}$ çalışmada, ayrık-dönüşlü Lidar noktaları, nokta tabanlı bir yaklaşımla sınıflara ayrılmıştır. KDH ağının giriş parametreleri, noktaya ait x-y-z koordinatları ve yoğunluk (intensity) bilgisidir. Yoğunluk bilgisi olarak üretilen raster 
görüntünün gri değerleri kullanılmıştır. Değişkenlere ait ortalama ve varyans değerleri birbirinden anlamlı derecede farklı olduğunda değişkenlerin 0-1 aralığına normalize edilmesi KDH’nin performansını arttırmaktadır. Giriş parametreleri Eşitlik 6 ile verilen, minimum-maksimum yöntemi ile normalize edildikten sonra $\mathrm{KDH}$ ile kümeleme işlemine geçilmiştir.

$X_{i}^{\prime}=\left(X_{i}-X_{\min }\right) /\left(X_{\max }-X_{\min }\right)$

Burada; $X_{i}^{\prime}$, normalizasyon değerini; $X_{i}$, öznitelik değerini; $X_{\min }$, en küçük öznitelik değerini ve $X_{\max }$, en büyük öznitelik değerini ifade etmektedir.

Normalize edilen veriler kullanılarak denetimsiz bir yapay sinir ağı yöntemi olan KDH yöntemiyle hava Lidar noktalarının sınıflandırılması aşağıdaki adımlar kullanılarak sağlanmıştır. İş akış diyagramı Şekil 2’de verilmiştir.

1) Sistematik bir şekilde az sayıda küme oluşturularak en etkili nokta sınıflandırılmasının belirlenmesi amaçlanmıştır. Bu nedenle, başlangıç nöron sayısı iki olarak belirlenmiştir. Bu bağlamda, küme sayısını veren ağın boyutuna kümeleme performansı göz önünde bulundurularak karar verilmiştir.

2) Kümelere ayrılan noktalar, uydu görüntüleri ile görsel olarak karşılaştırılarak etiketlendirilmiştir. Bu aşamada aynı nesne sınıfına ait nokta kümeleri birleştirilerek nokta sınıfları belirlenmiştir.

3) Tüm noktaların görsel olarak sınıflandırıldığı test verisi ile KDH yapay sinir ağı kullanılarak belirlenen nokta sınıfları karşılaştırılarak, zemine ait noktaların ve zemine ait olmayan noktaların sınıflandırılması, bir başka deyişle filtrelenmesi ile ilgili Tip-1, Tip-2 ve toplam hataları belirlenmiştir (Sithole \& Vosselman, 2003).

Tip 1 hatası $=b /(a+b)$

Tip 2 hatası $=c /(c+d)$

Toplam hata $=(b+c) / e$

Burada; $a$, doğru sınıflandırılmış zemine ait noktaları; $b$, zemine ait olmayan nokta olarak yanlış sınıflandırılmış zemine ait noktaları; $c$, zemine ait nokta olarak yanlış sınıflandırılmış zemine ait olmayan noktaları; $d$, doğru sınıflandırılmış zemine ait olmayan noktaları; $e$, toplam test nokta sayısını göstermektedir.

4) Noktaların tümünde genel anlamda filtrelemenin yeterli olması için toplam filtreleme hatasının tolerans değerini geçmemesi gerekmektedir. Yeterli doğruluğa ulaşılamaması durumunda ağ topolojisindeki nöron sayısı sırasıyla x ve y yönünde bir arttırılır.

5) Noktaların tümünde istenilen filtreleme doğruluğuna erişildikten sonra, küme bazında toplam filtreleme hatasının tolerans değerini geçmemesi gerekmektedir. Yeterli doğruluğa ulaşılamaması durumunda küme, alt kümelere ayrılmak amacıyla KDH yöntemi tekrar uygulanır.

\section{3. Çalışma Alanı ve Kullanılan Veriler}

Bu çalışmada, Harita Genel Müdürlüğü’nün başkanlığında 2014 y1lında üretilen, Riegl LMS-Q1560 Lidar sistemiyle İzmir iline bağlı Bergama ilçesinde 1200 metre yükseklikte gerçekleştirilen uçuş verilerinden elde edilen ayrık dönüşlü Lidar test verisi kullanılmıştır. Nokta doğruluğu 250 metrede 2 cm'dir. Nokta yoğunluğu 8 nokta/m²' dir (Kayı, Erdoğan, \& Eker, 2015). 
Seçilen çalışma alanı ilçe merkezinin dışında kırsal kesimde yer almakta ve pek çok düzensiz binayı, bitki örtüsünü ve geniş bir yolu içermektedir. Arazi eğimlidir ve binalar bu eğim üzerinde sıralanmıştır. İç içe yapılar arasında bulunan çatılardan uzanan saçaklar, farklı yükseklikteki yapı ve bahçe duvarları çalışma alanını filtreleme açısından karmaşık bir hale getirmektedir. Çalışma alanı 62 m x 120 m genişliğindedir. Toplam 46438 noktadan oluşmaktadır. Çalışma alanına ait Lidar nokta bulutunun 3B görünümü Şekil 3'te, alanın Google Earth uydu görüntüsü ve eğimi (76 m ile 95 m yükseklik değerleri arasında) Şekil 4'te ve Lidar verisinde sınıflandırma ve filtreleme performansını etkileyen hata kaynaklarından biri olan yapılara ait saçakların gösterildiği örnek görüntüler Şekil 5'te verilmiştir.

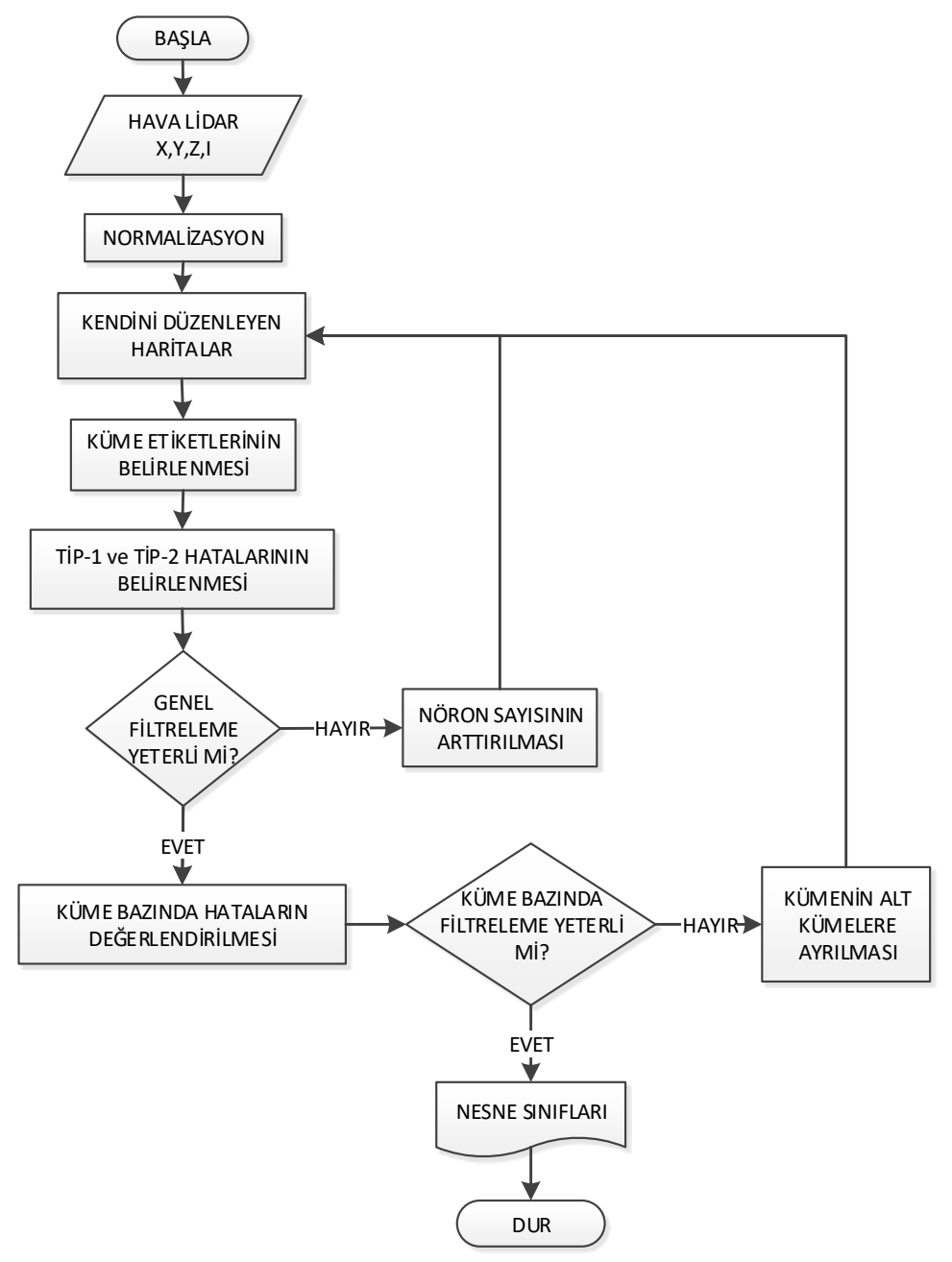

Şekil 2: Iş akış diyagramı

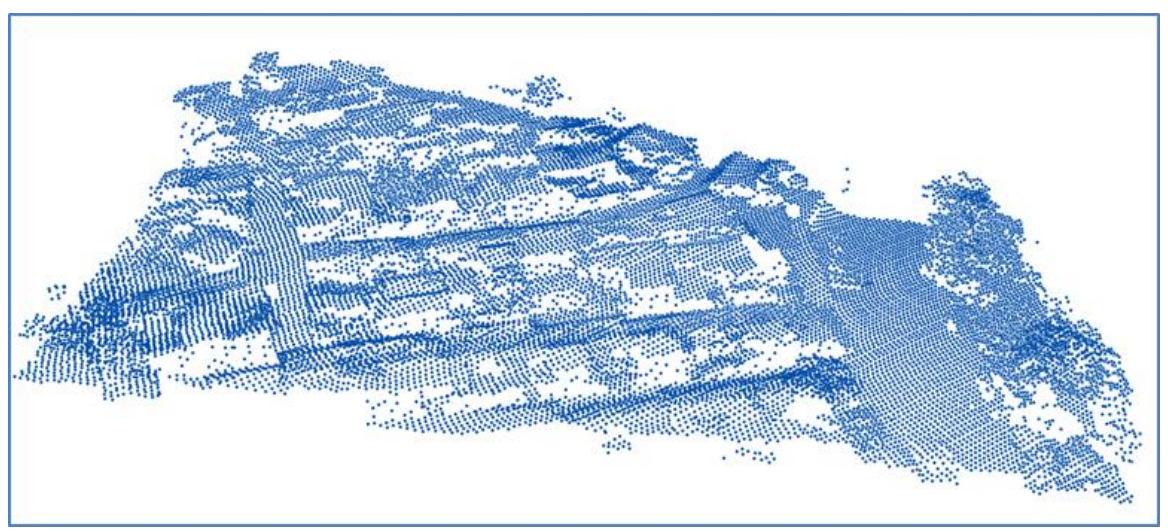

Şekil 3: Çalışma alanına ait Lidar nokta bulutunun 3B görünümü 


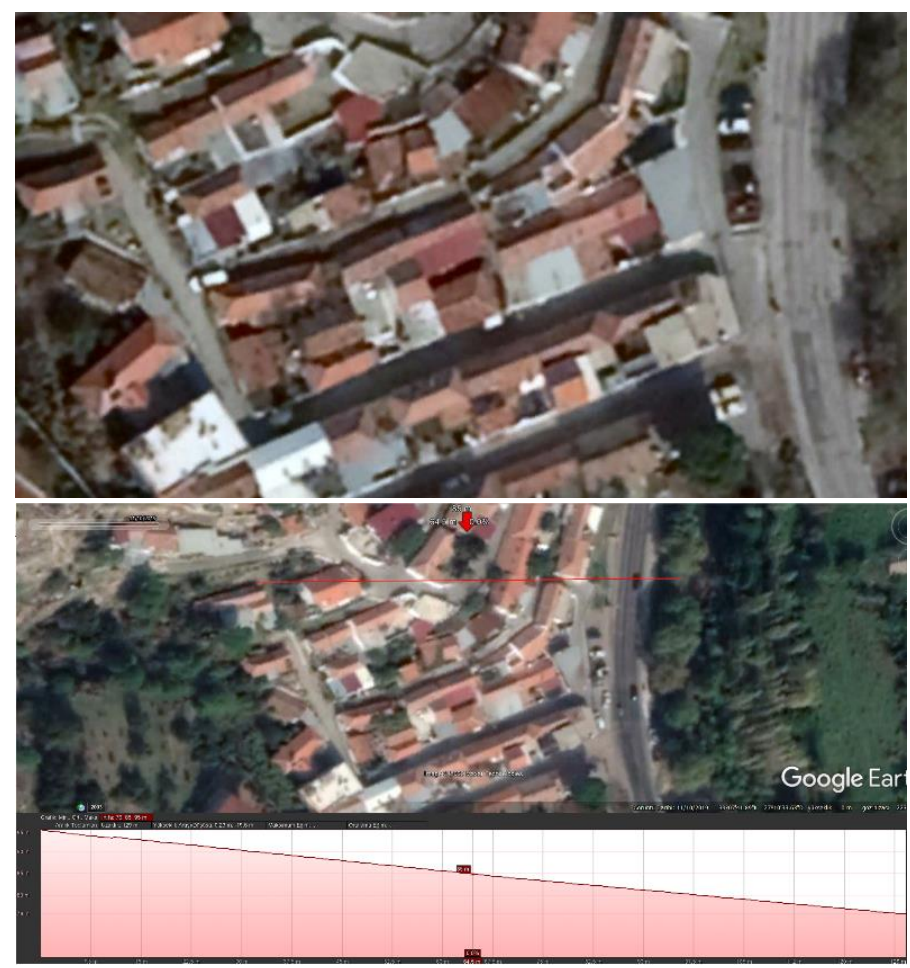

Şekil 4: Çalışma alanına ait Google Earth uydu görüntüsü ve eğimi
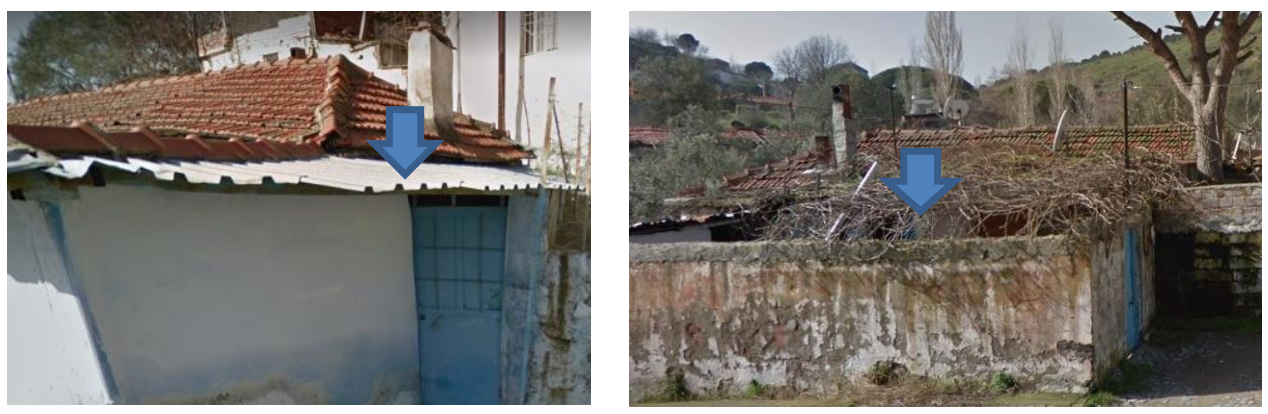

Şekil 5: Çalışma alanına ait yapı saçaklarını gösteren Google Map örnek sokak görüntüleri

\section{Hava Lidar Verisinin Kendini Düzenleyen Haritalar Yöntemiyle Filtrelenmesi}

Lidar veri setine ait noktaların x-y-z ve yoğunluk öznitelikleri ArcGIS 10.6 yazılımı kullanılarak elde edilmiştir. KDH fonksiyonu ile $x-y-z$ ve yoğunluk değişkenlerine göre kümeleme işlemi, hata hesabı ve nöron sayısı değişimini de içerecek biçimde, Matlab R2020a yazılımında bir kod yazılarak otomatik olarak gerçekleştirilmiştir. KDH ile oluşturulan küme etiketleri, ArcGIS 10.6 yazılımına aktarılmış, burada uydu görüntüleri ile karşılaştırılarak nesne sınıflarına karar verilmiştir. Böylece kullanılan KDH ağının performansı belirlenmiştir.

Noktaların genel olarak filtrelenmesi aşamasında en iyi performans, KDH topolojisi altıgen, boyutu ise $4 \times 5$ olarak sağlanmıştır. Ağın boyutu 4x5 olduğundan en fazla 20 nöron veya küme oluşabilmektedir. Ağın eğitimi sonrasında, örneklem toplam yirmi adet kümeye yerleşmiştir. İki bitki örtüsü kümesi görsel olarak birleştirilmiştir. Ayrıca yoğunluk ve yükseklik değerlerine ait ağırlıklar, $x$ ve y değerlerine göre 10 kat fazla alınmıştır. Şekil 6'da KDH ile genel anlamda kümeleme sonuçları gösterilmiştir.

Genel anlamda en iyi performansı sağlayan kümelemede, pek çok bina noktasının zemin noktasından ayrıldığı görülmüştür. Ancak bina noktaları ile ortalama aynı yüksekliğe sahip bitki örtüsü noktalarının karışı̆̆̆ı, ayrıca bazı bina noktalarının zemin 
sınıflarında yer aldığı tespit edilmiştir. Şekil 6'da mavi renkte görülen zemin sınıfına ait noktalar ile bina noktalarını daha iyi ayrıştırmak ve şeklin sol üst köşesinde kahverengi renkte görülen eğimin arttı̆̆ı yerde daha belirgin bir kümelenme oluşturmak için, söz konusu noktaları içeren altı küme, KDH ile üçer alt kümeye ayrılmıştır. Bu aşamada 3x1 boyutlu nöron ağ1 yeterli olmuştur. İkinci aşama sonucunda bina olarak sınıflandırılmayan pek çok nokta, Şekil 7'de görüldüğü gibi zemin ve bitki örtüsü noktalarından ayrılmıştır. Sınıfların kararlı aşamaya ulaşması için 200 iterasyonun yeterli olduğu görülmüştür.

Sistematik bir şekilde az sayıda küme oluşturularak en etkili nokta sınıflandırmasının belirlenmesi amaçlanmıştır. Bu nedenle en yüksek sınıflandırma doğruluna en az sayıda küme ile ulaşılmak istendiğinden, hata tolerans değeri \%20 ile sınırlı tutulmuştur. Daha düşük tolerans değerleri, nöron veya küme sayısını arttırmış ve görsel olarak yapılan kümelerin birleştirilmesi işlemini karmaşık hale getirmiştir.

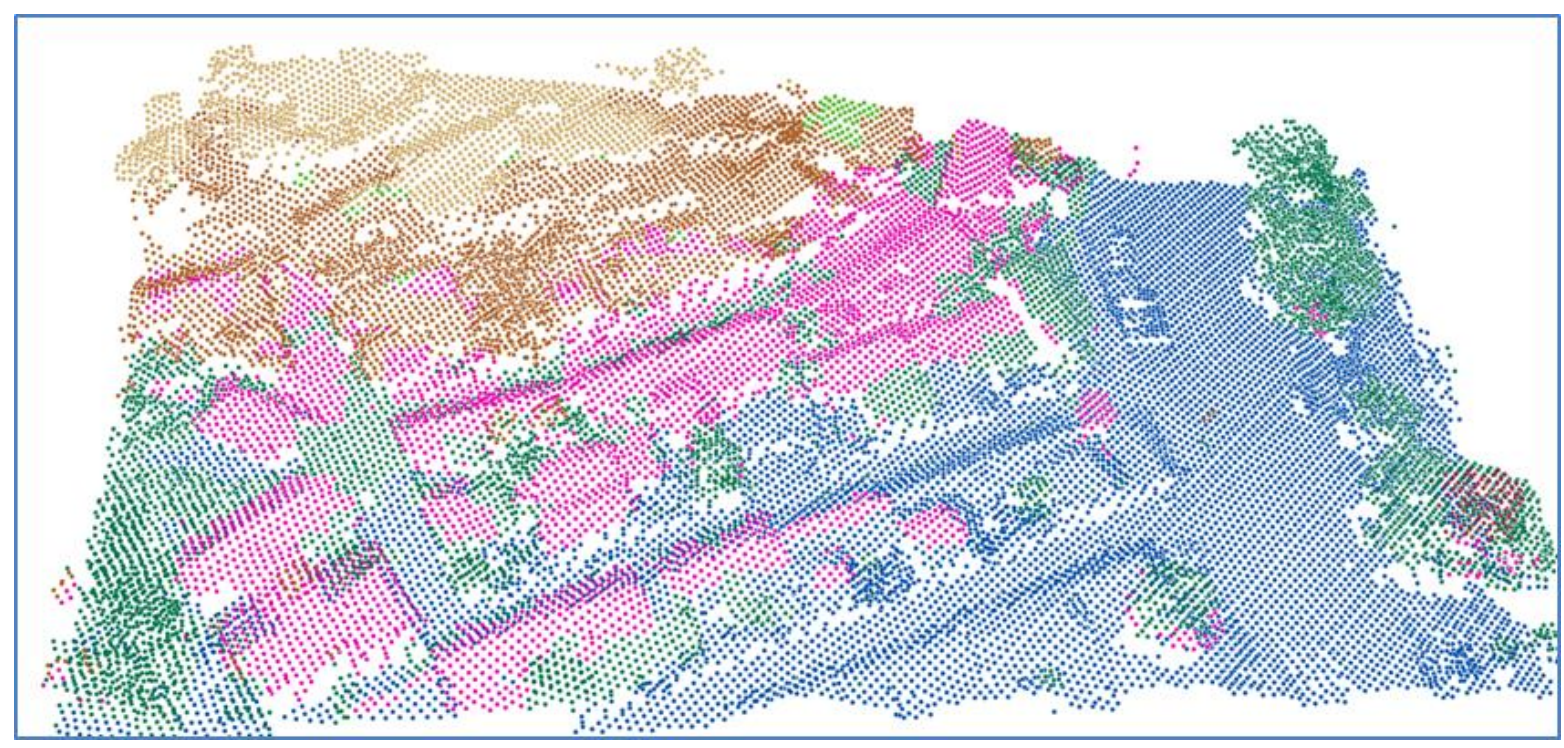

Şekil 6: KDH ile genel anlamda kümeleme sonuçları

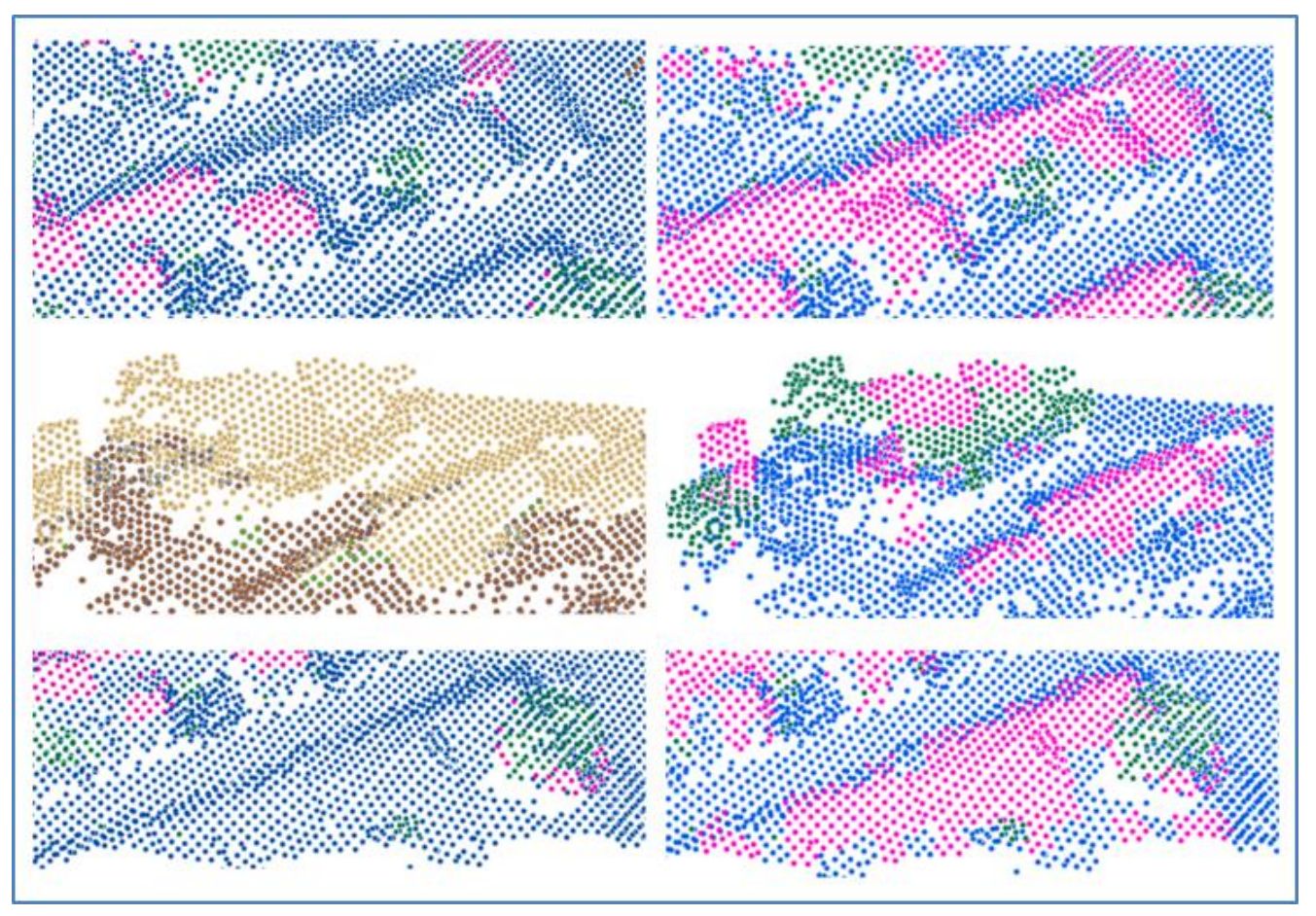

Şekil 7: KDH ile oluşturulan iki kümenin üçer alt kümeye ayrılması: (sol) öncesi (sağ) sonrası 


\section{Bulgular ve Tartışma}

Kümeler, aynı nesne türünü içerecek biçimde birleştirilerek sınıflandırılmıştır. Böylece bina, bitki örtüsü ve zemin sınıfları elde edilmiştir. Çalışma bölgesinde tüm noktaların sınıf doğruluğu uydu görüntüleri kullanılarak belirlenmiştir. Toplam 46438 noktanın 17821 'i bina, 10 865'i bitki örtüsü, 17 752'si zemine ait noktalardır. Tablo 1'de bina, bitki örtüsü ve zemin olmak üzere üç sınıfa ait sınıflandırma doğruluk yüzdeleri gösterilmiştir. Tablo 2’ de ise, noktaların filtrelenmesi ile ilgili Tip1, Tip-2 ve toplam hata oranı gösterilmiştir.

Tablo 1: Sınıflandırma matrisi

\begin{tabular}{|c|c|c|c|c|c|}
\hline & Filtreleme & Bina & Bitki Örtüsü & Zemin & Doğruluk \\
\hline \multirow{3}{*}{ 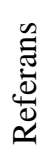 } & Bina & 13068 & 1123 & 3630 & $\% 73.33$ \\
\hline & Bitki Örtüsü & 82 & 8840 & 1943 & $\% 81.36$ \\
\hline & Zemin & 1631 & 418 & 15703 & $\% 88.46$ \\
\hline
\end{tabular}

Tablo 1'de diyagonal elemanlar doğru sınıflandırılan noktaları gösterirken, sütundaki diğer elemanlar hatalı sınıflandırılmış noktaları göstermektedir. Toplamda 46438 noktanın 37 611'i doğru sınıflandırılmıştır. KDH yöntemi ile sınıflandırmanın genel başarısı \%80.99'dur. Buna göre, toplam 17821 adet bina noktasının 13 068'i doğru sınıflandırılırken, 1123 'ü bitki örtüsü, 3630’u zemin olarak yanlış sınıflandırılmıştır. Bina noktalarının çıkarımı \% 73.33 başarılıdır. Sonuçlar, bir bina çıkarımı yöntemi olarak da yöntemin geliştirilebileceğini göstermiştir. Bitki örtüsüne ait toplam 10865 adet noktanın 8840 '1 doğru sınıflandırılırken, 82'si bina, 1943’ü zemin olarak yanlış sınıflandırılmıştır. Bitki örtüsünün çıkarımı \%81.36 başarılıdır. Günümüzde bitki örtüsüne ait noktaların analizinde tam dalga boyu formlu sistemler kullanılmaktadır. Ayrık dönüşlü sistemler, bitki örtüsüne ait noktaların çıkarımında tam dalga boyu formlu sistemlere göre daha zayıf kalsa da bu çalışmadaki performansı iyidir.

Tablo 2: Filtreleme ile ilgili hata oranları

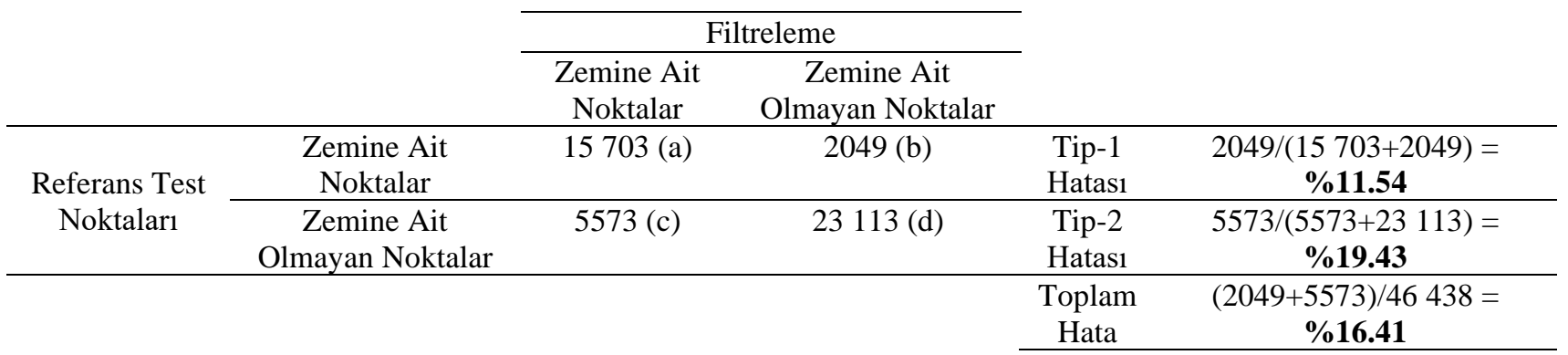

Tablo 1'de, toplam 17752 adet zemin noktasının 15 703'ü doğru sınıflandırılırken, 1631'i bina, 418'i bitki örtüsü olarak yanlış sınıflandırılmıştır. Zemin noktalarının çıkarımı \%88.46'dır. Uygulanan yöntemin filtreleme performansı iyi düzeydedir.

Tablo 2'de, Lidar nokta bulutunun denetimsiz bir yapay sinir ağı olan KDH yöntemiyle filtrelenmesi sonucu, zemine ait olmayan nokta olarak yanlış sınıflandırılmış zemine ait noktalardaki hatayı gösteren Tip-1 hatası \%11.54’tür. Bu oran ile Tablo 1'de görülen zemine ait noktaların çıkarımı oranının toplamı 100'e eşittir. Zemine ait nokta olarak yanlış sınıflandırılmış zemine ait olmayan noktalardaki hatayı gösteren Tip-2 hatası \%19.43'tür. Toplam filtreleme hatası ise \%16.41 olarak bulunmuştur.

Hata tolerans değerinin \%20 eşik değerden yüksek olduğu kümelere alt kümeler oluşturmak amacıyla ikinci kez KDH uygulanmış ve tüm kümelerde istenilen doğruluk değerlerine ulaşılmıştır. Sonuçlar görsel olarak değerlendirildiğinde Şekil 
8'de A kutucuğunda yer alan küme üç alt kümeye ayrılarak zemine karışan bina noktaları doğru sınıflandırılmıştır. B kutucuklarında yer alan kümeler üçer alt kümeye ayrılarak zemine karışan bitki örtüsü doğru sınıflandırılmıştır. C kutucuğunda yer alan küme üç alt kümeye ayrılarak bitki örtüsüne karışan zemin noktaları doğru sınıflandırılmıştır. Ancak D kutucuğunda yer alan bitki örtüsüne karışan bina noktalarının sınıflandırılabilmesi için daha fazla sayıda alt küme oluşturulması gerektiği gözlemlenmiştir.

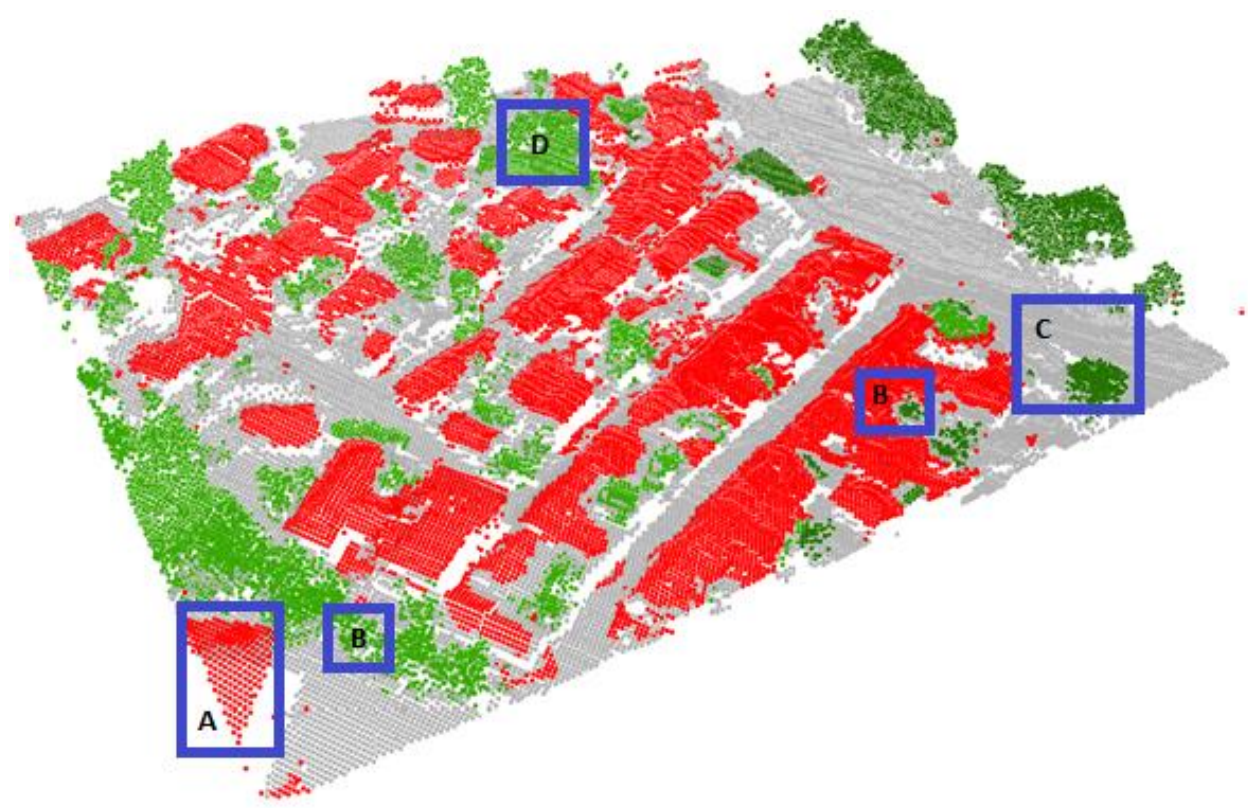

Şekil 8: KDH yöntemiyle sınıflandırılan zemin (gri), bina (kırmızı) ve bitki örtüsü (yeşil) noktaları

Şekil 9'da doğru sınıflandırılan zemin noktaları açık gri renk ile, doğru sınıflandırılan zemine ait olmayan noktalar koyu gri renk ile, Tip-1 hatası mavi renk ile ve Tip-2 hatası kırmızı renk ile gösterilmiştir. Genellikle hatalar eğimin arttı̆̆ı yerde, binalar arasında bulunan bahçe duvarlarından ve çatılardan uzanan saçaklardan kaynaklanmaktadır.

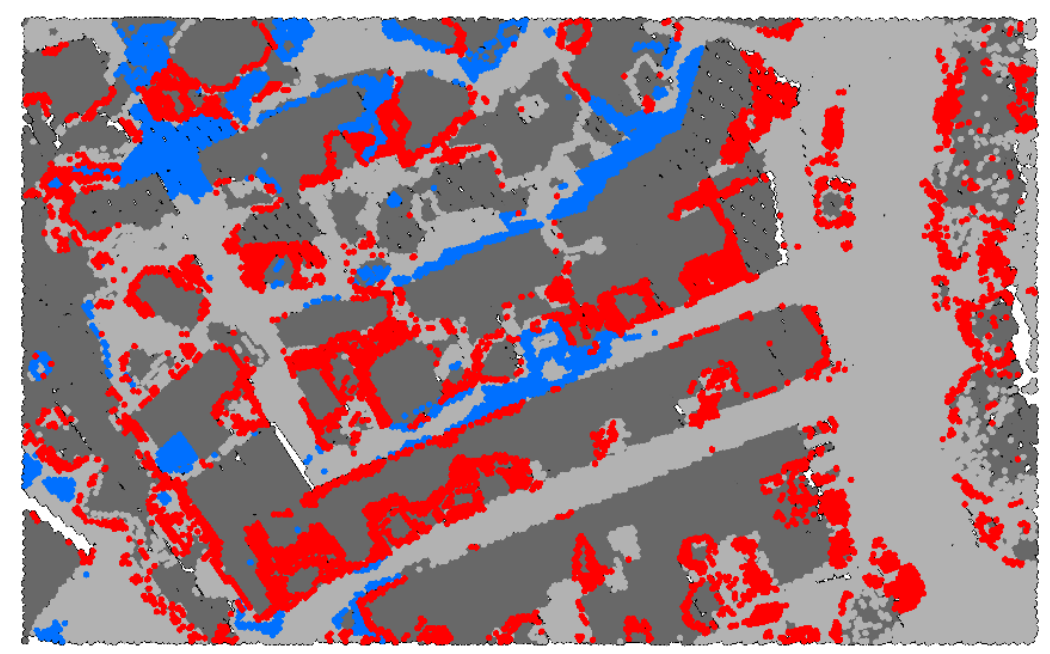

Şekil 9: . Doğru sınıflandırılan zemin noktaları (açık gri), doğru sınıflandırılan zemine ait olmayan noktalar (koyu gri), Tip-1 hatası (mavi) ve Tip-2 hatası (kırmızı) 


\section{Sonuç ve Öneriler}

Mekansal bilgilerin Lidar verilerinden elle işlenilen yöntemlerle, görsel olarak çıkarılması işlemi kapsamlı, maliyetli ve zaman alıcıdır. Denetimsiz bir yapay sinir ağı yöntemi olan KDH yönteminin avantajı, doğrusal olmayan ve büyük boyutlu girdi vektörlerini, daha az boyutlu bir uzaya (çıktı katmanına) izdüşürme yeteneğine sahip olmasıdır. KDH'nin bu avantajı kullanılarak, genellikle doğrusal olmayan bir problem olarak değerlendirilebilecek Lidar veri setinin filtrelenmesi, Tip-1 hatası \%11.54, Tip-2 hatası \%19.43 ve toplam hata \%16.41 bulunarak yüksek doğrulukla gerçekleştirilmiştir.

Sithole ve Vosselman (2003)'e ait benzer bir çalışma alanında kullanılan çeşitli filtreleme yöntemlerinde, Tip-1 hatası \%15.96 ile \%62 arasında değişirken; Tip-2 hatası \%2.41 ile \%12.17 arasında değişmiştir. Toplam hata ise \%10.76 ile \%36.96 arasında değişmiştir. KDH yöntemi ile elde edilen filtreleme sonuçları, \%11.54 Tip-1 hatasının ve \%16.41 toplam hatanın günümüzde kullanılan başarılı filtreleme yöntemlerinin performansını yakaladığını göstermiştir.

Hata tolerans değeri tanımlanarak sağlanan denetimli deney sonuçlarına göre pek çok zemin ve bina noktası doğru sınıflandırılmış olsa da, özellikle arazi eğiminden ve iç içe yapılar arasında bulunan bahçe duvarları ve çatılardan uzanan saçaklardan kaynaklı bazı bina noktalarının zemin noktalarından ayrılamadığı tespit edilmiştir. Ayrıca aynı yüksekliğe sahip bazı bina noktaları bitki örtüsü sınıfında yer almıştır. KDH’nin çok boyutlu veri girişi sayesinde, üç boyutlu koordinatların yanında dördüncü bir boyut olan yoğunluk değerlerinin kullanılabilmesi ile özellikle eğim farkının olduğu alanlarda sınıflandırma doğruluğu olumlu yönde etkilenmiştir.

Yöntemin dezavantajı ise, tüm kümeleme yöntemlerinde olduğu gibi oluşan kümelerin birleştirilmesi ve etiketlenmesi işlemidir. Çok sayıda küme oluştuğunda, birleştirme işılemi karmaşık bir hale dönüşmektedir. Bu yüzden en az sayıda küme oluşturularak, en etkili nokta sınıflandırılmasının belirlenmesi amaçlanmış ve buna göre hata tolerans değeri \%20 olarak belirlenmiştir. Genel kümeleme işleminde 4x5 (20 nöron) nöron ağının, alt kümelemede ise 3x1 (3 nöron) nöron ağının yeterli olduğu görülmüştür. Gelecek çalışmalarda, kümelerin otomatik birleştirilmesine yönelik çalışmalar geliştirilerek yöntemin performansı attırılabilir.

Sonuç olarak, SYM üretimi için ihtiyaç duyulan hava Lidar verilerinin otomatik olarak filtrelenmesi ile zemin noktalarının çıkarımında denetimsiz bir yapay sinir ağı olan $\mathrm{KDH}$ yönteminin belirlenen nöron sayısı ile etkin olarak kullanılabildiği görülmüştür.

\section{Teşekkür}

Bergama ilçesine ait Lidar test uçuş verilerini sağlayan Harita Genel Müdürlüğü’ne teşekkürü bir borç biliriz.

\section{Yazar Katkısı}

Alper Şen: Fikir, Tasarım, Literatür Taraması, Denetleme, Yazım, Makale değerlendirme. Burcu Bayaslı: Veri toplama ve işleme, Analiz ve yorumlama.

\section{Kaynaklar}

Briese, C. (2010). Extraction of digital terrain models. Vosselman, G., \& Maas, H.-G.(ed) Airborne and terrestrial laser scanning (s.135- 
167). Dunbeath, UK: Whittles Publishing.

Chen, Q., Wang, H., Zhang, H., Sun, M., \& Liu, X. (2016). A point cloud filtering approach to generating DTMs for steep mountainous areas and adjacent residential areas. Remote sensing, 8(1), 71.

Chen, Z., Gao, B., \& Devereux, B. (2017). State-of-the-art: DTM generation using airborne LIDAR data. Sensors, 17(1), 150.

Giampouras, P., Charou, E., \& Kesidis, A. (2013). Artificial Neural Network Approach for Land Cover Classification of Fused Hyperspectral and Lidar Data. Papadopoulos, H., Andreou, A.S., Iliadis, L., \& Maglogiannis, I.(ed) IFIP International Conference on Artificial Intelligence Applications and Innovations (s. 255-261). Berlin, Heidelberg: Springer.

Grebby, S., Naden, J., Cunningham, D., \& Tansey, K. (2011). Integrating airborne multispectral imagery and airborne LiDAR data for enhanced lithological mapping in vegetated terrain. Remote Sensing of Environment, 115(1), 214-226.

Kang, X., Liu, J., \& Lin, X. (2014). Streaming progressive TIN densification filter for airborne LiDAR point clouds using multi-core architectures. Remote sensing, 6(8), 7212-7232.

Kay1, A., Erdoğan, M., \& Eker, O. (2015). OPTECH HA-500 ve RIEGL LMS-Q1560 ile gerçekleştirilen LİDAR test sonuçları. Harita Dergisi, 153(2), 42-46.

Kohonen, T. (1990). The Self-Organizing Map. Proceedings of the IEEE, 78, 1464-1480.

Kohonen, T. (2001). Self-organizing maps. Berlin, Almanya: Springer.

Kwon, S. K., Jung, H. S., Baek, W. K., \& Kim, D. (2017). Classification of forest vertical structure in south Korea from aerial orthophoto and lidar data using an artificial neural network. Applied Sciences, 7(10), 1046.

Mongus, D., \& Žalik, B. (2014). Computationally efficient method for the generation of a digital terrain model from airborne LiDAR data using connected operators. IEEE journal of selected topics in applied earth observations and remote sensing, 7(1), 340-351.

Morris, J. T., Porter, D., Neet, M., Noble, P. A., Schmidt, L., Lapine, L. A., \& Jensen, J. R. (2005). Integrating LIDAR elevation data, multi-spectral imagery and neural network modelling for marsh characterization. International Journal of Remote Sensing, 26(23), 5221-5234.

Salah, M., Trinder, J., \& Shaker, A. (2009). Evaluation of the self-organizing map classifier for building detection from lidar data and multispectral aerial images. Journal of Spatial Science, 54(2), 15-34.

Şen, A., Süleymanoğlu, B., \& Soycan, M. (2020). Unsupervised extraction of urban features from airborne lidar data by using selforganizing maps. Survey Review, 52(371), 150-158.

Sithole, G., \& Vosselman, G. (2003). Report: ISPRS Comparison of Filters. Commission III, Working Group 3. https://www.itc.nl/isprs/wgIII-3/filtertest/report05082003.pdf.

Sithole, G., \& Vosselman, G. (2004). Experimental comparison of filter algorithms for bare-Earth extraction from airborne laser scanning point clouds. ISPRS journal of photogrammetry and remote sensing, 59(1-2), 85-101.

Skupin, A., \& Agarwal, P. (2008). Introduction: What is a Self-Organizing Map? Agarwal, P., \& Skupin, A.(ed) Self-organising maps: Applications in geographic information science (s. 1-20). Chichester, UK: John Wiley \& Sons.

Yan, J., \& Thill, J.-C. (2008). Visual exploration of spatial interaction data with self-organizing maps. Agarwal, P., \& Skupin, A.(ed) Selforganising maps: Applications in geographic information science (s. 67-85). Chichester, UK: John Wiley \& Sons.

Zaletnyik, P., Laky, S., \& Toth, C. (2010). LiDAR waveform classification using self-organizing map. ASPRS, 28-30.

Zhang, J., Lin, X., \& Ning, X. (2013). SVM-based classification of segmented airborne LiDAR point clouds in urban areas. Remote Sensing, 5(8), 3749-3775. 